\title{
Late Effects from Hadron Therapy
}

Eleanor A. Blakely ${ }^{1}$ and Polly Y. Chang ${ }^{2}$

${ }^{1}$ Life Sciences Division, Lawrence Berkeley National Laboratory, Berkeley, CA 94720-8174 USA

${ }^{2}$ Biosciences Division, SRI International, Menlo Park, CA 94025 USA

Total \# of pages: 20

Number of figures: 0

Number of Tables: 0

Running head: Late Effects from Hadron Therapy (35 characters)

Key words: late effects, hadron therapy, carbon, protons

\section{Corresponding Author:}

Dr. Eleanor A. Blakely

MS 70A-1118.

Life Science Division

Lawrence Berkeley National Laboratory,

Berkeley, CA 94620

USA

Telephone: (510) 486-6595

FAX: (510) 486-4475

Email: EABlakely@lbl.gov 


\section{Abstract}

Successful cancer patient survival and local tumor control from hadron radiotherapy warrant a discussion of potential secondary late effects from the radiation. The study of late-appearing clinical effects from particle beams of protons, carbon, or heavier ions is a relatively new field with few data. However, new clinical information is available from pioneer hadron radiotherapy programs in the USA, Japan, Germany and Switzerland. This paper will review available data on late tissue effects from particle radiation exposures, and discuss its importance to the future of hadron therapy.

Potential late radiation effects are associated with irradiated normal tissue volumes at risk that in many cases can be reduced with hadron therapy. However, normal tissues present within hadron treatment volumes can demonstrate enhanced responses compared to conventional modes of therapy. Late endpoints of concern include induction of secondary cancers, cataract, fibrosis, neurodegeneration, vascular damage, and immunological, endocrine and hereditary effects. Low-dose tissue effects at tumor margins need further study, and there is need for more acute molecular studies underlying late effects of hadron therapy. 


\section{Introduction}

Hadron therapy is the use of charged particle beams of protons or carbon ions for radiotherapeutic treatment of disease or abnormal conditions. Hadron therapy holds promise due to its ability to deliver high doses of radiation to sharply defined target volumes. Heavier particles have a somewhat diminished depth-dose profile, but enhanced biological effectiveness. This is a rapidly growing field as witnessed by the growing number of patients treated with proton (up to 33,398 ) or heavy ion (up 3,860 ) beams, and the growing number of new facilities currently under construction throughout the world [103]. This is particularly true for proton accelerators, but is significantly more limited for facilities capable of accelerating heavier ions such as carbon. There are currently twenty-four proton facilities worldwide, and nearly twenty more planned, while there are just three carbon facilities currently treating patients, one in Germany and two in Japan, but five future heavy-ion facilities are planned in both Europe and Asia.

There have been some editorial discussions on both sides of the cost-benefit-analysis of hadron therapy (compared to X-ray radiation therapy), and how successful its move from the laboratory to the clinic has been $[45,46,50,97]$. At issue is the fact that operating technology for accelerators in the laboratory can be underestimated in the transition to the clinic. However, recent reports of overall higher local control and cure rates following hadron therapy $[24,30,32,38,70,72,80,81,83,98,101,107]$ have drawn attention to these modalities, and justify a consideration of potential late radiation effects in surviving patients. The goal of this paper is to summarize the few clinical and experimental data that are available, and to suggest areas of need for further study.

\section{Radiation sensitivity among adult human organs}

lonizing radiation injures normal cells and tissues through various molecular pathways. In general, the radiation sensitivity of a given tissue, and in turn of a given organ, depends on the radiation sensitivity of the key cells in the system. Radiosensitive organs with approximate tolerance doses of less than 2 Gy (beyond which there is a high probability of delayed injury within 5 years) include the testis, lens, and ovary. Organs with mid-range sensitivity ( $<30 \mathrm{~Gy}$ ) by this index include kidney, lung, bone marrow and liver. More radioresistant organs (<60 Gy) are spinal cord, intestine, urinary bladder, and bone [37]. The brain has historically been considered a radioresistant organ, but recent novel assessments of stem cells in the brain have triggered a reevaluation of the radiosensitivity of specific brain compartments [110].

Also important in radiation sensitivity are several physical and biological variable: dose size, dose mode (internal or external), dose-rate, fractionation, size of the irradiated field, time of observation after exposure, and condition of the stroma and vascular supply. The implementation of hadron therapy has stimulated estimates of not only the absorbed physical dose, but also a biologically weighted dose that includes a medical decision and clinical judgement [115]. The ICRU has made recommendations for international standardization of these units for protons [51]. The ICRU has another report in preparation regarding prescribing, recording and reporting proton beam therapy.

\section{Acute versus late effects}

Radiation lesions demonstrate differences in their temporal appearance. Immediate injury of radiosensitive cells is usually associated with DNA damage in the rapidly proliferating cells. Progressive necrosis and loss of epithelial cells occurs with denudation of villi, hemopoietic, spermatogonia and spermatocyte depletion in the early phase within days of an exposure. 
Recovery processes begin with repair and repopulation of stem cell pools within individual tissue compartments and continue for months. Delayed effects begin months to years after the exposure with atrophy, necrosis, metaplasia, atypia, dysplasia and neoplasia in epithelial compartments, fibrosis, fibrinous exudate, atypical fibroblasts, and lack of cellular inflammatory response in stromal compartments, and finally alterations in capillaries and arterioles in the vascular compartment. For successful radiotherapy, the most important aspect is often finding the balance between cure and late effects (see [33])

Radiations with enhanced ionization densities can cause both quantitative and qualitative differences in cells and tissues compared to radiations with sparse ionization $[8,15,17,118,120]$. At issue for this paper are differences in late tissue effects induced by gamma rays, protons, helium, carbon or heavier ions. Due to its earlier clinical establishment, proton therapy has a longer follow-up experience than carbon ion therapy. Biological studies with experimental systems are still ongoing for both radiation types.

\section{Proton and helium radiation therapy}

The superior radiation depth-dose profiles due to the physical characteristics of proton and helium beams can be used to treat small volumes of tissue very precisely, while sparing surrounding normal tissues. Many of the initial radiotherapeutic uses of protons have been to treat lesions in the head and neck region. An elegant demonstration of the precision of the proton beam is the work of Reder et al [91] who studied the physiology and morphology of the cat lateral geniculate nucleus (LGN) following proton irradiation. The LGN is a structure with well-defined anatomical boundaries, and well-described afferent, efferent, and receptive field properties. Reder et al. [91] used a $1.0 \mathrm{~mm}$ proton microbeam to determine short-term (3 month), and long-term (9 month) receptive field effects of irradiation on LGN relay cells after 16, 40, or $60 \mathrm{~Gy}$. Following irradiation, abnormalities in receptive field organization were found in 40 and 60 Gy short-term animals, and in all of the long-term animals. The abnormalities included "silent" areas of the LGN receptive fields. Histologic analysis failed to identify cellular necrosis or vascular damage in the irradiated LGN, but revealed a disruption in retinal afferents to areas of the LGN. Unexpectedly, the area and extent of neural function increased with time, having larger effects with longer post-irradiation time suggesting that cellular mechanisms initiated by protons continued for extended time after exposure.

The treatment of human lesions with protons or helium ions was pioneered in Berkeley, Uppsala, Sweden, Harvard and in the former Soviet Union (see review in $[89,90]$ ). There is an impressive literature in particular with regard to treatment of chordoma/chondrosarcoma $[12,21,22,32,80,84,92,95,105,107]$, meningiomas [59, 114] and choroidal melanoma [24, 28, 29, $34,48,89,92]$. Combinations of photons with a proton boost have been shown to offer an exceptional chance of cure at the price of an acceptable toxicity [83]. Few detailed reports of late morbidities following proton therapy [113] have been reported. Experimental studies looking at dose-volume effects in the rat cervical spinal cord after proton irradiation showed steeply increasing $\mathrm{ED}_{50}$ values for lengths of less than $8 \mathrm{~mm}$ [14]. The results suggested the presence of a critical migration distance of 2-3 mm for cells involved in regeneration processes.

Tumors in numerous additional organs of the body have been treated with protons or helium ions for evaluation of tolerance and therapeutic efficacy, including liver [7, 73, 74], stomach [62, 100], esophagus [63], lung [101], prostate [102, 104], pancreas and biliary duct [122] and gynecologic sites [6]. 
A more significant issue for evaluation of proton therapy is: which photon modality should be the gold standard therapy for comparisons with protons? Conformal proton radiotherapy (PRT) has been compared to three-dimensional (3-D) planned photons in evaluation of limiting dose to auditory structures [69] and brain lesions [9]. The conclusions drawn indicate that for simple geometries or for superficial lesions, there is no advantage in using protons. However, for complex planning target volumes (PTV), or when the PTV is in the vicinity of critical structures, protons seen to be potentially better than for the fixed-field photon technique. In the case of posterior fossa conformity, 3D photons came at the expense of increasing amounts of normal tissue receiving low to moderate doses, whereas PRT resulted in increased dose sparing of normal structures. However tumor recurrence was neither prevented nor noticeably delayed in dose-escalation Phase I/II trials with proton/photon irradiation compared to published series on photon irradiation for Daumas-Duport lower-grade [38].

Intensity modulated radiotherapy (IMRT) is one of the newest photon developments allowing nearly ideal delivery of photon beams. The promise of this innovation is much greater local control rates with reduced morbidity [26] and see summary of recent International 3D-CRT/IMRTWorkshop [52]. However, Hall and Wuu, [49] point out that the move from 3D-conformal radiotherapy to IMRT involves more fields, and the dose-volume histograms show that as a consequence, a larger volume of normal tissue is exposed to lower doses, and there is increased total body exposure from leakage radiation. Both of these factors would increase the risk of second cancers. This risk is especially an issue for pediatric neuro-oncology [71]. With regard to proton therapy for pediatric cranial tumors, early treatment-related morbidity associated with proton therapy is low and decreased long-term toxicity in the maturing child is expected $[43,75]$. A comparative analysis of the incidence of secondary cancer after therapy for Hodgkin's disease with photon or proton radiation indicated that IMRT has little or no improvement over conventional treatments. However, proton treatments could result in a significantly lower cancer incidence than photon treatments, and this result appeared to be independent of the delivery technique [94]. Anecdotal increased head and neck tumors have been reported for proton-irradiated rodents and non-human primates [31, 121].

Additional late effects of protons or helium include cataract-induction [16, 35, 47, 68, 77, 82] late retinal cell damage [117], endothelial cell loss in retinal microvessels [5] and optic nerve (125), loss of endocrine function [104] and immunological deficits [54$56,88]$. The majority of these studies conclude that late effects induced by protons or helium ions are nearly equivalent to what one would expect from equivalent photon doses. Proton RBE values are 1.0, except near the very end of the stopping Bragg peak [10, $11,13,44,53,86,87]$

In conclusion, there is strong evidence supporting the use of proton radiotherapy as superior even to IMRT [40] and perhaps even as a replacement for external beam radiation therapy [106].

\section{Carbon ion beam radiation therapy}

One would expect that late radiation effects from densely ionizing radiations like carbon or neon ions may be a greater risk that late effects from less densely ionizing radiations. The neutron experience taught us that late effects of high-LET radiations can have a higher RBE than the acute effects from neutrons [119]. A handicap in the evaluation of late effects is that the follow-up time of patients treated with carbon or neon ions is considerably shorter than patients treated with protons $[23,25,57,70,78,79,98,99$, 111, 112]. 
The choice of tumors to be treated with carbon ion beams, and the modes of delivery have been different for the three facilities currently treating patients. At the HIMAC facility in Chiba, Japan, and the HYOGO ion beam medical center in Hyogo, Japan, carbon beam radiotherapy uses wobbler magnets and a scatterer to flatten the radiation field. The depth-dose distribution of the beam is modified with passive beam filters to spread-out the Bragg peak [58]. The Japanese program has concentrated primarily on tumors of the chest and abdomen (lung, liver, uterine cervix, and prostate), and also treated head and neck patients. Overall carbon treatment schedules have been successfully shortened to one to three weeks for liver and lung cancer, which minimized the proliferation of tumor cells during treatments [58]. The Japanese program was a pioneer in the development of particle beam delivery gated to respiration. The Japanese program also uses RBE determinations from the laboratory, and modified by clinical judgement to implement their beam delivery $[42,53,108]$.

In contrast, the German carbon ion program ongoing in Darmstadt, Germany uses active beam shaping by scanning in 3D [18, $64,65]$. The German program has restricted their carbon radiotherapy to tumors of the head and neck. This conservative approach was important to their assessment of the active beam delivery in organs without body motion. The German program uses a theoretical model of local effect to estimate biological effect of the carbon ions based on laboratory measurements and clinical judgements $[66,67,96,116]$

For all of the reasons mentioned above, much of what is known about late effects of heavier ion beams has largely been obtained in the laboratory, and clinical impressions from the earlier neon clinical trials in Berkeley [25]. Late effects on the brain [60, 61] and spinal cord [85] have been emphasized, and the data show evidence indicating that the RBE values for single-dose irradiations of the brain and spinal cord are within the experimental uncertainty. It was noted that vascular dilatation, erythrocytic stagnation and hyperpermeability are evident in the delayed injury to the spinal cord [85]. Changes in bone volume after irradiation have also been noted and linked to differential modulation of radiation-induced growth factor expression [93].

Significant differences in RBE values are obtained with carbon ions depending on the radiation quality and the biological model studied [41, 108] and accelerated reoxygenation has been reported after fractionated carbon ions, compared to -rays [2]. Significant and rapid tissue remodeling has been reported for heavy-ion damage compared to low-LET radiation in vivo [36] and in cells in vitro [39]. The induction of gene and protein expression patterns are also LET-dependent [3, 4, 20, 27, 76, 109]. Finally tumor induction is increased by high-LET radiations $[1,19]$.

In conclusion, the significance of the increased biological effectiveness of heavy ions is a two-edged sword. There is clinical evidence for efficacy in the treatment of non-squamous cell histology such as adenocarcinoma, adenoid cystic carcinoma, and malignant melanoma, early stage and locally advanced non-small cell lung cancer, hepatoma, and bone/soft tissue sarcoma. Radioresistant, slow-growing tumors also respond. However, if the carbon treatment volume includes normal tissues, they too are at risk for the appearance of both enhanced acute and late radiation effects. The skill of the physicist is required to assure optimal treatment plans for reduction of extraneous dose to normal tissues surrounding the tumor target, but carbon ions hold the potential for significant clinical advantage not achievable with protons.

\section{Summary}


New radiation modalities require many years for full evaluation of late-appearing effects. Proton therapy has survived this gauntlet, and evidence for its efficacy in the clinic now indicates it may well be superior even to the best photons has to offer (IMRT) for deep and complicated tumor sites. Late tissue normal tissue toxicities do not appear to be an issue for proton therapy. Carbon ion therapy currently has a shorter follow-up, and in fact it is premature to draw clinical conclusions regarding long-term normal tissue toxicities. However, early clinical evidence is mounting that indicates there is a place for ion-beam therapy where tumor radiation resistance to proton therapy is an issue. Careful carbon treatment planning has led to acceptable acute normal tissue reactions, and late reactions are currently under scrutiny. One deficiency for both proton and carbon ion therapies has been the lack of information on the course of metastatic disease. Overall, it may be that the radiation oncologist would select protons for specific discreet deep lesions in some tissues, and carbon ions for specific discreet lesions in other tissues of the body, but that neither modality alone may be adequate for diffuse, highly metastatic lesions. 
Acknowledgements

This work was supported by NASA \#T-465X. 


\section{References}

[1] Alpen, EL, Powers-Risius, P, Curtis, SB and DeGuzman, R, Tumorigenic potential of high-Z, high-LET charged-particle radiations, Radiat Res, 1993; 136 (3): 382-391.

[2] Ando, K, Koike, S, Ohira, C, et al., Accelerated reoxygenation of a murine fibrosarcoma after carbon-ion radiation, Int J Radiat Biol, 1999; 75 (4): 505-512.

[3] Ando, S, Nojima, K, Ishihara, $\mathrm{H}$, et al., Induction by carbon-ion irradiation of the expression of vascular endothelial growth factor in lung carcinoma cells, Int J Radiat Biol, 2000; 76 (8): 1121-1127.

[4] Ando, S, Nojima, K, Majima, H, et al., Evidence for mRNA expression of vascular endothelial growth factor by X-ray irradiation in a lung squamous carcinoma cell line, Cancer Lett, 1998; 132 (1-2): 75-80.

[5] Archambeau, JO, Mao, XW, McMillan, PJ, et al., Dose response of rat retinal microvessels to proton dose schedules used clinically: a pilot study, Int J Radiat Oncol Biol Phys, 2000; 48 (4): 1155-1166.

[6] Arimoto, T, Kitagawa, T, Tsujii, $\mathrm{H}$ and Ohhara, K, High-energy proton beam radiation therapy for gynecologic malignancies. Potential of proton beam as an alternative to brachytherapy., Cancer., 1991; 68(1): 79-83.

[7] Austin-Seymour, M, Chen, G, Castro, J, et al., Dose volume histogram analysis of liver radiation tolerance., Int J Radiat Oncol Biol Phys., 1986; 12(1): 31-35.

[8] Barcellos-Hoff, MH and Brooks, AL, Extracellular signaling through the microenvironment: a hypothesis relating carcinogenesis, bystander effects, and genomic instability, Radiat Res, 2001; 156 (5 Pt 2): 618-627.

[9] Baumert, BG, Lomax, AJ, Miltchev, V and Davis, JB, A comparison of dose distributions of proton and photon beams in stereotactic conformal radiotherapy of brain lesions, Int J Radiat Oncol Biol Phys, 2001; 49 (5): 1439-1449.

[10] Belli, M, Bettega, D, Calzolari, P, et al., Inactivation of human normal and tumour cells irradiated with low energy protons, Int J Radiat Biol, 2000; 76 (6): 831-839.

[11] Belli, M, Campa, A and Ermolli, I, A semi-empirical approach to the evaluation of the relative biological effectiveness of therapeutic proton beams: the methodological framework, Radiat Res, 1997; 148 (6): 592-598.

[12] Berson, A, Castro, J, Petti, P, et al., Charged particle irradiation of chordoma and chondrosarcoma of the base of skull and cervical spine: the Lawrence Berkeley Laboratory experience., Int J Radiat Oncol Biol Phys., 1988; 15(3): 559-565.

[13] Bettega, D, Calzolari, P, Chauvel, P, et al., Radiobiological studies on the $65 \mathrm{MeV}$ therapeutic proton beam at Nice using human tumour cells, Int J Radiat Biol, 2000; 76 (10): 1297-1303.

[14] Bijl, HP, van Luijk, P, Coppes, RP, Schippers, JM, Konings, AW and van der Kogel, AJ, Dose-volume effects in the rat cervical spinal cord after proton irradiation, Int J Radiat Oncol Biol Phys, $2002 ; 52$ (1): 205-211.

[15] Blakely, E, Biological effects of cosmic radiation: deterministic and stochastic., Health Phys., 2000; 79(5): $495-506$.

[16] Blakely, E, Daftari, I, Meecham, W, et al., Helium-ion-induced human cataractogenesis., Adv Space Res., 1994; 14(10): 501-505.

[17] Blakely, EA and Kronenberg, A, Heavy-ion radiobiology: new approaches to delineate mechanisms underlying enhanced biological effectiveness, Radiat Res, 1998; 150 (5 Suppl): S126-145.

[18] Brusasco, C, Voss, B, Schardt, D, Kramer, M and Kraft, G, A dosimetry system for fast measurement of 3D depth-dose profiles in charged-particle tumor therapy with scanning techniques, Nuclear Instruments and Methods in Physics Research, 2000; B (168): 578-592.

[19] Burns, FJ, Jin, Y, Garte, SJ and Hosselet, S, Estimation of risk based on multiple events in radiation carcinogenesis of rat skin, Adv Space Res, 1994; 14 (10): 507-519.

[20] Calaf, G and Hei, TK, Oncoprotein expression in human breast epithelial cells transformed by high-LET radiation, Int $\mathrm{J}$ Radiat Biol, 2001; 77 (1): 31-40.

[21] Castro, J, Collier, J, Petti, P, et al., Charged particle radiotherapy for lesions encircling the brain stem or spinal cord., Int J Radiat Oncol Biol Phys., 1989; 17(3): 477-484.

[22] Castro, J, Linstadt, D, Bahary, J, et al., Experience in charged particle irradiation of tumors of the skull base: 1977-1992., Int J Radiat Oncol Biol Phys., 1994; 29(4): 647-655.

[23] Castro, JR, Results of heavy ion radiotherapy, Radiat Environ Biophys, 1995; 34 (1): 45-48.

[24] Castro, JR, Char, DH, Petti, PL, et al., 15 years experience with helium ion radiotherapy for uveal melanoma, Int J Radiat Oncol Biol Phys, 1997; 39 (5): 989-996.

[25] Castro, JR, Phillips, TL, Prados, M, et al., Neon heavy charged particle radiotherapy of glioblastoma of the brain, Int J Radiat Oncol Biol Phys, 1997; 38 (2): 257-261.

[26] Cella, L, Lomax, A and Miralbell, R, Potential role of intensity modulated proton beams in prostate cancer radiotherapy, Int J Radiat Oncol Biol Phys, 2001; 49 (1): 217-223.

[27] Chang, PY, Bjornstad, KA, Chang, E, et al., Particle irradiation induces FGF2 expression in normal human lens cells, Radiat Res, 2000; 154 (5): 477-484.

[28] Char, D, Castro, J, Kroll, S, Irvine, A, Quivey, J and Stone, R, Five-year follow-up of helium ion therapy for uveal melanoma., Arch Ophthalmol., 1990; 108(2): 209-214.

[29] Char, D and Miller, T, Orbital pseudotumor. Fine-needle aspiration biopsy and response to therapy., Ophthalmology., 1993; 100(11): 1702-1710.

[30] Courdi, A, Caujolle, JP, Grange, JD, et al., Results of proton therapy of uveal melanomas treated in Nice, Int J Radiat Oncol Biol Phys, 1999; 45 (1): 5-11.

[31] Dalrymple, GV, Leichner, PK, Harrison, KA, et al., Induction of high grade astrocytoma (HGA) by protons: molecular mechanisms and RBE considerations, Adv Space Res, 1994; 14 (10): 267-270.

[32] Debus, J, Schulz-Ertner, D, Schad, L, et al., Stereotactic fractionated radiotherapy for chordomas and chondrosarcomas of the skull base, Int J Radiat Oncol Biol Phys, 2000; 47 (3): 591-596.

[33] Donaldson, S, Hancock, S and Hoppe, R, The Janeway lecture. Hodgkin's disease--finding the balance between cure and late effects., Cancer J Sci Am., 1999; 5(6): 325-333.

[34] Egger, E, Schalenbourg, A, Zografos, L, et al., Maximizing local tumor control and survival after proton beam radiotherapy of uveal melanoma, Int J Radiat Oncol Biol Phys, 2001; 51 (1): 138-147. 
[35] Egger, E, Zografos, L, Munkel, G, Bohringer, T, Bercher, L and Chamot, L, Results of proton radiotherapy for uveal melanomas., Front Radiat Ther Oncol., 1997; 30: 111-122.

[36] Ehrhart, EJ, Gillette, EL and Barcellos-Hoff, MH, Immunohistochemical evidence of rapid extracellular matrix remodeling after iron-particle irradiation of mouse mammary gland, Radiat Res, 1996; 145 (2): 157-162.

[37] Fajardo L.-G., LF, Berthrong, M and Anderson, RE, in Radiation Pathology, ed. Fajardo L.-G., LF, Berthrong, M and Anderson, RE. Oxford University Press, 2001; Pages.

[38] Fitzek, MM, Thornton, AF, Harsh, Gt, et al., Dose-escalation with proton/photon irradiation for Daumas-Duport lowergrade glioma: results of an institutional phase I/II trial, Int J Radiat Oncol Biol Phys, 2001; 51 (1): 131-137.

[39] Fournier, C, Scholz, M, Weyrather, WK, Rodemann, HP and Kraft, G, Changes of fibrosis-related parameters after highand low-LET irradiation of fibroblasts, Int J Radiat Biol, 2001; 77 (6): 713-722.

[40] Fowler, J, What can we expect from dose escalation using proton beams?, Clin Oncol (R Coll Radiol). 2003; 15(1): S1015.

[41] Fukutsu, K, Kanai, T, Furusawa, Y and Ando, K, Response of mouse intestine after single and fractionated irradiation with accelerated carbon ions with a spread-out Bragg peak, Radiat Res, 1997; 148 (2): 168-174.

[42] Furusawa, Y, Fukutsu, K, Aoki, M, et al., Inactivation of aerobic and hypoxic cells from three different cell lines by accelerated (3)He-, (12)C- and (20)Ne-ion beams, Radiat Res, 2000; 154 (5): 485-496.

[43] Fuss, M, Hug, EB, Schaefer, RA, et al., Proton radiation therapy (PRT) for pediatric optic pathway gliomas: comparison with 3D planned conventional photons and a standard photon technique, Int J Radiat Oncol Biol Phys, 1999; 45 (5): 1117 1126.

[44] Gerweck, LE and Kozin, SV, Relative biological effectiveness of proton beams in clinical therapy, Radiother Oncol, 1999; 50 (2): 135-142.

[45] Goitein, M and Jermann, M, The relative costs of proton and X-ray radiation therapy, Clin Oncol (R Coll Radiol), $2003 ; 15$ (1): S37-50.

[46] Gottschalk, B, Koehler, AM and Wilson, R, Weighing proton therapy's clinical readiness and costs, Physics Today, 2003; $56(6): 10$.

[47] Gragoudas, E, Egan, K, Walsh, S, Regan, S, Munzenrider, J and Taratuta, V, Lens changes after proton beam irradiation for uveal melanoma., Am J Ophthalmol. 1995 Feb;119(2):157-64., 1995; 119(2): 157-164.

[48] Gragoudas, E, Seddon, J, Goitein, M, et al., Current results of proton beam irradiation of uveal melanomas., Ophthalmology., 1985; 92(2): 284-291.

[49] Hall, E and Wuu, C, Radiation-induced second cancers: the impact of 3D-CRT and IMRT., Int J Radiat Oncol Biol Phys., 2003; 56(1): 83-88.

[50] Halperin, EC, Overpriced technology in radiation oncology, Int J Radiat Oncol Biol Phys, $2000 ; 48$ (4): $917-918$.

[51] ICRU,Clinical proton dosimetry. Part 1: Beam production, beam delivery and measurement of absorbed dose. 1998, ICRU.

[52] IMRT, International 3D-CRT/IMRTWorkshop, Int J Radiat Oncol Biol Phys., 2003; 56(1).

[53] Kagawa, K, Murakami, M, Hishikawa, Y, et al., Preclinical biological assessment of proton and carbon ion beams at Hyogo Ion Beam Medical Center, Int J Radiat Oncol Biol Phys, 2002; 54 (3): 928-938.

[54] Kajioka, E, Andres, M, Li, J, et al., Acute effects of whole-body proton irradiation on the immune system of the mouse., Radiat Res., 2000; 153(5 Pt 1): 587-594.

[55] Kajioka, E, Andres, M, Mao, X, Moyers, M, Nelson, G and Gridley, D, Hematological and TGF-beta variations after wholebody proton irradiation., In Vivo., 2000; 14(6): 703-708.

[56] Kajioka, E, Gheorghe, C, Andres, M, et al., Effects of proton and gamma radiation on lymphocyte populations and acute response to antigen., In Vivo., 1999; 13(6): 525-533.

[57] Kamada, T, Tsujii, H, Tsuji, H, et al., Efficacy and safety of carbon ion radiotherapy in bone and soft tissue sarcomas, J Clin Oncol, 2002; 20 (22): 4466-4471.

[58] Kanai, T, Endo, M, Minohara, S, et al., Biophysical characteristics of HIMAC clinical irradiation system for heavy-ion radiation therapy, Int J Radiat Oncol Biol Phys, 1999; 44 (1): 201-210.

[59] Kaplan, I, Castro, J and Phillips, T, Helium charged particle radiotherapy for meningioma: experience at UCLBL. University of California Lawrence Berkeley Laboratory., Int J Radiat Oncol Biol Phys., 1994; 28(1): 257-261.

[60] Karger, CP, Debus, J, Peschke, P, Munter, MW, Heiland, S and Hartmann, GH, Dose-response curves for late functional changes in the normal rat brain after single carbon-on doses evaluated by magnetic resonance imaging: influence of follow-up time and calculation of relative biological effectiveness, Radiat Res, 2002; 158 (5): 545-555.

[61] Karger, CP, Munter, MW, Heiland, S, Peschke, P, Debus, J and Hartmann, GH, Dose-response curves and tolerance doses for late functional changes in the normal rat brain after stereotactic radiosurgery evaluated by magnetic resonance imaging: influence of end points and follow-up time, Radiat Res, 2002; 157 (6): 617-625.

[62] Koyama, S, Kawanishi, N, Fukutomi, H, et al., Advanced carcinoma of the stomach treated with definitive proton therapy., Am J Gastroenterol., 1990; 85(4): 443-447.

[63] Koyama, S, Tsujii, H, Yokota, H, et al., Proton beam therapy for patients with esophageal carcinoma., Jpn J Clin Oncol., 1994; 24(3): 144-153.

[64] Kraft, G, Tumor therapy with heavy charged particles, Progress in Particle and Nuclear Physics, 2000; 45: S473-S544

[65] Kraft, G, Tumortherapy with ion beams, Nuclear Instruments and Methods in Physics Research, 2000; A (454): 1-10.

[66] Kramer, M, Jakel, O, Haberer, T, Kraft, G, Schardt, D and Weber, U, Treatment planning for heavy-ion radiotherapy: physical beam model and dose optimization, Phys Med Biol, 2000; 45 (11): 3299-3317.

[67] Kramer, M and Scholz, M, Treatment planning for heavy-ion radiotherapy: calculation and optimization of biologically effective dose, Phys Med Biol, 2000; 45 (11): 3319-3330.

[68] Lett, J, Lee, A and Cox, A, Late cataractogenesis in rhesus monkeys irradiated with protons and radiogenic cataract in other species., Radiat Res., 1991; 126(2): 147-156.

[69] Lin, R, Hug, EB, Schaefer, RA, Miller, DW, Slater, JM and Slater, JD, Conformal proton radiation therapy of the posterior fossa: a study comparing protons with three-dimensional planned photons in limiting dose to auditory structures, Int $\mathrm{J}$ Radiat Oncol Biol Phys, 2000; 48 (4): 1219-1226. 
[70] Linstadt, DE, Castro, JR and Phillips, TL, Neon ion radiotherapy: results of the phase I/II clinical trial, Int J Radiat Oncol Biol Phys, 1991; 20 (4): 761-769.

[71] Loeffler, JS, Kooy, HM and Tarbell, NJ, The emergence of conformal radiotherapy: special implications for pediatric neuro-oncology, Int J Radiat Oncol Biol Phys, 1999; 44 (2): 237-238.

[72] Loeffler, JS, Smith, AR and Suit, HD, The potential role of proton beams in radiation oncology, Semin Oncol, 1997; 24 (6): 686-695.

[73] Matsuzaki, Y, Osuga, T, Chiba, T, et al., New, effective treatment using proton irradiation for unresectable hepatocellular carcinoma., Intern Med., 1995; 34(4): 302-304.

[74] Matsuzaki, Y, Osuga, T, Saito, Y, et al., A new, effective, and safe therapeutic option using proton irradiation for hepatocellular carcinoma., Gastroenterology., 1994 Apr;; 106(4): : 1032-1041.

[75] McAllister, B, Archambeau, J, Nguyen, M, et al., Proton therapy for pediatric cranial tumors: preliminary report on treatment and disease-related morbidities., Int J Radiat Oncol Biol Phys., 1997; 39(2): 455-460.

[76] McNamara, MP, Bjornstad, KA, Chang, PY, Chou, W, Lockett, SJ and Blakely, EA, Modulation of lens cell adhesion molecules by particle beams, Phys Med, 2001; 17 Suppl 1: 247-248.

[77] Meecham, W, Char, D, Kroll, S, Castro, J and Blakely, E, Anterior segment complications after helium ion radiation therapy for uveal melanoma. Radiation cataract., Arch Ophthalmol., 1994; 112(2): 197-203.

[78] Miyamoto, T, Yamamoto, N, Koto, M, Nishimura, H, Tsujii, H and Fujisawa, T, [Heavy-ion therapy for non-small cell lung cancer], Nippon Geka Gakkai Zasshi, 2002; 103 (2): 250-255.

[79] Miyamoto, T, Yamamoto, N, Nishimura, H, et al., Carbon ion radiotherapy for stage I non-small cell lung cancer, Radiother Oncol, 2003; 66 (2): 127-140.

[80] Munzenrider, JE and Liebsch, NJ, Proton therapy for tumors of the skull base, Strahlenther Onkol, 1999 ; 175 Suppl 2: 5763.

[81] Nakano, T, Suzuki, M, Abe, A, et al., The phase I/II clinical study of carbon ion therapy for cancer of the uterine cervix, Cancer J Sci Am, 1999; 5 (6): 362-369.

[82] Niemer-Tucker, M, Sterk, C, de Wolff-Rouendaal, D, et al., Late ophthalmological complications after total body irradiation in non-human primates., Int J Radiat Biol., 1999; 75(4): 465-472.

[83] Noel, G, Habrand, JL, Mammar, H, et al., Combination of photon and proton radiation therapy for chordomas and chondrosarcomas of the skull base: the Centre de Protontherapie D'Orsay experience, Int J Radiat Oncol Biol Phys, 2001; 51 (2): 392-398.

[84] Nowakowski, V, Castro, J, Petti, P, et al., Charged particle radiotherapy of paraspinal tumors., Int J Radiat Oncol Biol Phys., 1992; 22(2): 295-303.

[85] Okada, S, Okeda, R, Matsushita, S and Kawano, A, Histopathological and morphometric study of the late effects of heavy-ion irradiation on the spinal cord of the rat, Radiat Res, 1998; 150 (3): 304-315.

[86] Paganetti, $\mathrm{H}$ and Goitein, M, Radiobiological significance of beamline dependent proton energy distributions in a spreadout Bragg peak, Med Phys, 2000; 27 (5): 1119-1126.

[87] Paganetti, H, Niemierko, A, Ancukiewicz, M, et al., Relative biological effectiveness (RBE) values for proton beam therapy, Int J Radiat Oncol Biol Phys, 2002; 53 (2): 407-421.

[88] Pecaut, M, Gridley, D and Nelson, G, Long-term effects of low-dose proton radiation on immunity in mice: shielded vs. unshielded., Aviat Space Environ Med., 2003; 74(2): 115-124.

[89] Raju, M, Proton radiobiology, radiosurgery and radiotherapy., Int J Radiat Biol., 1995; 67(3): 237-259.

[90] Raju, M, Particle radiotherapy: historical developments and current status., Radiat Res., 1996; 145(4): $391-407$.

[91] Reder, CS, Moyers, MF, Lau, D and Kirby, MA, Studies of physiology and the morphology of the cat LGN following proton irradiation, Int J Radiat Oncol Biol Phys, 2000; 46 (5): 1247-1257.

[92] Saunders, W, Chen, G, Austin-Seymour, M, et al., Precision, high dose radiotherapy. II. Helium ion treatment of tumors adjacent to critical central nervous system structures., Int J Radiat Oncol Biol Phys., 1985; 11(7): 1339-1347.

[93] Sawajiri, M and Mizoe, J, Changes in bone volume after irradiation with carbon ions, Radiat Environ Biophys, 2003.

[94] Schneider, U, Lomax, A and Lombriser, N, Comparative risk assessment of secondary cancer incidence after treatment of Hodgkin's disease with photon and proton radiation, Radiat Res, 2000; 154 (4): 382-388.

[95] Schoenthaler, R, Castro, J, Halberg, F and Phillips, T, Definitive postoperative irradiation of bile duct carcinoma with charged particles and/or photons., Int J Radiat Oncol Biol Phys., 1993; 27(1): 75-82.

[96] Scholz, M, Kellerer, AM, Kraft-Weyrather, W and Kraft, G, Computation of cell survival in heavy ion beams for therapy. The model and its approximation, Radiat Environ Biophys, 1997; 36 (1): 59-66.

[97] Schulz, RJ and Kagan, AR, Weighing proton therapy's clinical readiness and costs, Physics Today, $2003 ; 56$ (6): 10.

[98] Schulz-Ertner, D, Haberer, T, Jakel, O, et al., Radiotherapy for chordomas and low-grade chondrosarcomas of the skull base with carbon ions, Int J Radiat Oncol Biol Phys, 2002; 53 (1): 36-42.

[99] Schulz-Ertner, D, Nikoghosyan, A, Jakel, O, et al., Feasibility and toxicity of combined photon and carbon ion radiotherapy for locally advanced adenoid cystic carcinomas, Int J Radiat Oncol Biol Phys, 2003; 56 (2): 391-398.

[100] Shibuya, S, Takase, Y, Aoyagi, H, et al., Definitive proton beam radiation therapy for inoperable gastric cancer: a report of two cases., Radiat Med., 1991; 9(1): 35-40.

[101] Shioyama, Y, Tokuuye, K, Okumura, T, et al., Clinical evaluation of proton radiotherapy for non-small-cell lung cancer, Int J Radiat Oncol Biol Phys, 2003; 56 (1): 7-13.

[102] Shipley, W, Verhey, L, Munzenrider, J, et al., Advanced prostate cancer: the results of a randomized comparative trial of high dose irradiation boosting with conformal protons compared with conventional dose irradiation using photons alone., Int J Radiat Oncol Biol Phys., 1995; 32(1): 3-12.

[103] Sisterson, JM,PARTICLES Newsletter. 2003, Particle Therapy Co-Operative Group (PTCOG). p. 1-10.

[104] Slater, JD, Yonemoto, LT, Rossi, CJ, Jr., et al., Conformal proton therapy for prostate carcinoma, Int J Radiat Oncol Biol Phys, 1998; 42 (2): 299-304.

[105] Suit, H, Goitein, M, Munzenrider, J, et al., Definitive radiation therapy for chordoma and chondrosarcoma of base of skull and cervical spine., J Neurosurg., 1982; 56(3): 377-385. 
[106] Suit, HD, Protons to replace photons in external beam radiation therapy?, Clin Oncol (R Coll Radiol), 2003 ; 15 (1): S2931.

[107] Suit, HD, Goitein, M, Munzenrider, J, et al., Increased efficacy of radiation therapy by use of proton beam, Strahlenther Onkol, 1990; 166 (1): 40-44.

[108] Suzuki, M, Kase, Y, Kanai, T and Ando, K, Change in radiosensitivity with fractionated-dose irradiation of carbon-ion beams in five different human cell lines, Int J Radiat Oncol Biol Phys, 2000; 48 (1): 251-258.

[109] Takahashi, A, Ohnishi, K, Tsuji, K, et al., WAF1 accumulation by carbon-ion beam and alpha-particle irradiation in human glioblastoma cultured cells, Int J Radiat Biol, 2000; 76 (3): 335-341.

[110] Tofilon, P and Fike, J, The radioresponse of the central nervous system: a dynamic process., Radiat Res., 2000; 153(4): 357-370.

[111] Tsuji, H, Miyamoto, T, Mizoe, J, et al., Phase I/II dose escalation study with Carbon ions at NIRS, Physica Medica, 1998; XIV (Supplement 1, July): 70-75.

[112] Tsujii, H, Morita, S, Miyamoto, T, et al., Preliminary results of Phase I/II Carbon-ion therapy at the National Institute of Radiological Sciences, Journal of Brachytherapy International, 1977; 13: 1-8.

[113] Urie, MM, Fullerton, B, Tatsuzaki, H, et al., A dose response analysis of injury to cranial nerves and/or nuclei following proton beam radiation therapy, Int J Radiat Oncol Biol Phys, 1992; 23 (1): 27-39.

[114] Vernimmen, FJ, Harris, JK, Wilson, JA, Melvill, R, Smit, BJ and Slabbert, JP, Stereotactic proton beam therapy of skull base meningiomas, Int J Radiat Oncol Biol Phys, 2001; 49 (1): 99-105.

[115] Wambersie, A, Menzel, H, Gahbauer, R, Jones, D, Michael, B and Paretzke, H, Biological weighting of absorbed dose in radiation therapy., Radiat Prot Dosimetry., 2002; 99(1-4): 445-452.

[116] Weyrather, WK, Ritter, S, Scholz, M and Kraft, G, RBE for carbon track-segment irradiation in cell lines of differing repair capacity, Int J Radiat Biol, 1999; 75 (11): 1357-1364.

[117] Williams, G and Lett, J, Damage to the photoreceptor cells of the rabbit retina from 56Fe ions: effect of age at exposure, 1., Adv Space Res., 1996; 18(1-2): 55-58.

[118] Withers, H, Biological basis of radiation therapy for cancer., Lancet., 1992; 339(8786): 156-159.

[119] Withers, H, Thames HD, PetersLJ:, Differences in the fractionation response of acute and late responding tissues., in Progress in Radio-Oncology II, pp 287-296. New York, Raven Press,, Karcher, K, Kogelnik HD, Reinartz, G (eds),, Editor. Raven Press. 1982. 287-296.

[120] Withers, H, Thames, HJ, Hussey, D, Flow, B and Mason, K, Relative biological effectiveness (RBE) of $50 \mathrm{MV}(\mathrm{Be})$ neutrons for acute and late skin injury., Int J Radiat Oncol Biol Phys. 1978 Jul-Aug;4(7-8):603-8., 1978; 4(7-8): 603-608.

[121] Wood, D, Cox, A, Hardy, K, Salmon, $Y$ and Trotter, R, Head and neck tumors after energetic proton irradiation in rats, Adv Space Res, 1994; 14 (10): 681-684.

[122] Zurlo, A, Lomax, A, Hoess, A, et al., The role of proton therapy in the treatment of large irradiation volumes: a comparative planning study of pancreatic and biliary tumors, Int J Radiat Oncol Biol Phys, 2000; 48 (1): 277-288. 